\title{
When Thinking About Work Makes Employees Reach for Their Devices: A Longitudinal Autoregressive Diary Study
}

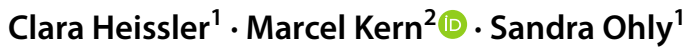

Accepted: 1 November 2021 / Published online: 28 January 2022

(c) The Author(s) 2022

\begin{abstract}
Based on the stressor-detachment model, previous research has assumed that work-related ICT use in the evening impairs psychological detachment. However, since most of the studies to date have assessed cross-sectional relationships, little is known about the actual direction of effects. In this 5-day diary study, we implemented a day-level longitudinal model to shed light on the causal relationships between work-related ICT use, detachment, and task progress $(N=340$ employees, $N=1289$ day-level cases). We also investigated the role of unfinished work tasks because we assumed, based on boundary theory, that they are a driving force leading to impaired detachment and work-related ICT use in the evening. Contrary to current research consensus but in line with our expectations, we found that low psychological detachment increased work-related ICT use and task progress. We found no evidence for reversed lagged effects. These results applied both to planned and unplanned ICT use. Furthermore, our results support the notion that unfinished work tasks precede ICT use and detachment. Thus, our findings suggest that work-related ICT use should not be treated as a stressor in its own right in the stressor-detachment model. Instead, it needs to be investigated as a behavioral outcome that employees engage in when they cannot detach from work.
\end{abstract}

Keywords Detachment · Work-related technology use · ICT use · Technology · Supplemental work · Unfinished tasks · Longitudinal autoregressive model · Diary study

Work-related information and communication technology (ICT) use is widely portrayed as contributing to employee stress and preventing employee recovery even outside

\section{An earlier version of this paper has been published in the best paper proceedings of the 2018 Academy of Management conference in Chicago, IL. Furthermore, we would like to thank Jana Kühnel and Laura Venz for their helpful suggestions in the preparation of this manuscript. This work has been funded by the Social Link Project within the Loewe Program of Excellence in Research, Hessen, Germany.}

Marcel Kern

kern@psych.uni-frankfurt.de

Clara Heissler

claraheissler@gmx.de

Sandra Ohly

ohly@uni-kassel.de

1 Department of Business Psychology, University of Kassel, Pfannkuchstraße 1, 34121 Kassel, Germany

2 Department of Psychology, Goethe University Frankfurt, Theodor-W.-Adorno-Platz 6, 60629 Frankfurt, Germany regular working hours. Scholars have therefore not tired from pointing out the risks ICT might bring to the home domain as well as to the workplace (Boswell \& OlsonBuchanan, 2007; Derks et al., 2015; Lanaj et al., 2014; Middleton, 2008). Considering that the work-related use of ICT during leisure time is increasingly pervasive (American Psychological Association, 2013), research is called upon to gain a deeper understanding of the processes through which work-related ICT use affects employee recovery and well-being.

A theoretical framework for research in this area is the stressor-detachment model (Sonnentag \& Fritz, 2015), according to which psychological detachment is impaired when individuals face high stressors at work. Oftentimes, work-related ICT use in the evening (also called technologyassisted supplemental work) has been conceptualized as a stressor in the model (e.g., Derks et al., 2014a, 2014b; Eichberger et al., 2020; see also Duranová \& Ohly, 2016). It has been argued that detachment, defined as the sense of being physically and mentally away from work (Etzion et al., 1998; Sonnentag \& Fritz, 2007), is impaired by ICT use because it 
Fig. 1 The conceptual withinperson research model. Dashed lines refer to autoregressive effects

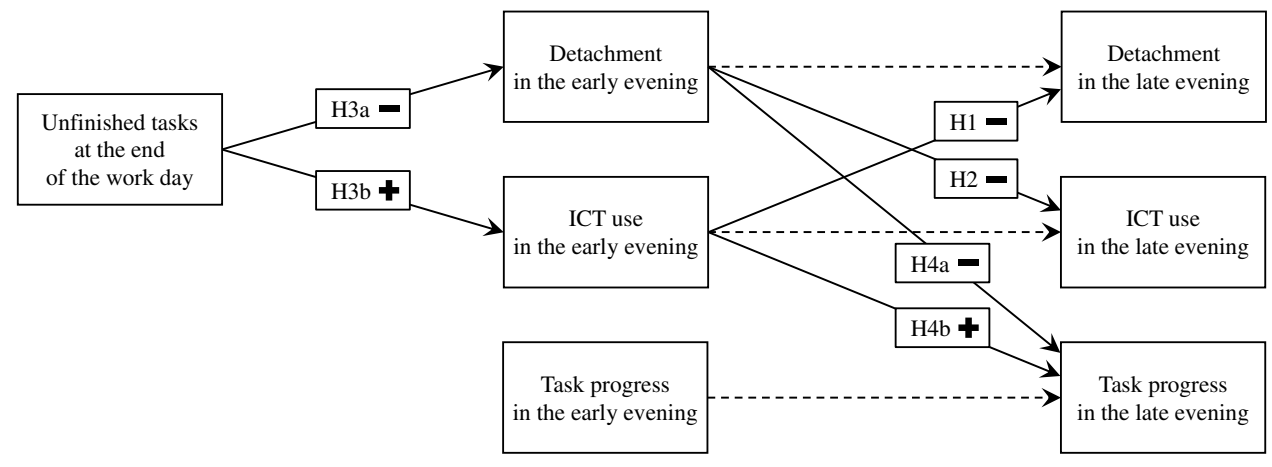

keeps work-related thoughts activated and prevents the individual from mentally switching off. This notion has received considerable support. For example, Derks et al. (2014b) and Eichberger et al. (2020) linked daily ICT use after hours to lack of detachment in the evening, and indirectly to higher levels of exhaustion.

Despite the fact that many previous studies have employed experience sampling methods, such as daily diaries, they have mostly examined cross-sectional relationships between detachment and ICT use (i.e., the study variables were assessed at the same time). Thus, we do not know if ICT use was the actual cause or rather the consequence of poor detachment. However, it is just as likely that ICT use may result from a lack of detachment, which dovetails with Sonnentag and Fritz's (2015) proposition in the stressordetachment model that impaired detachment can also induce dysfunctional behaviors such as continued work. Support is provided by a recent meta-analysis that found detachment to be negatively associated with contextual performance (Wendsche \& Lohmann-Haislah, 2017), indicating that low detachment triggers "additional work-related activities" (p. 16) such as ICT use, what reverses the effect mentioned above. Such behavioral consequences of lack of detachment, however, have hardly been researched so far within the stressor-detachment model, which originally sought to explain well-being.

In this paper, we strive to integrate these two perspectives by suggesting that the process between ICT use and detachment in the evening is reciprocal: ICT use for work after hours can be considered as an antecedent but also a behavioral consequence of poor detachment. A deeper understanding of work-related predictors, reasons, and outcomes of ICT use is important: in theoretical terms, clarifying the role of a concept and identifying true causal effects is at the heart of social science. In practical terms, it is essential to know the true source of lack of detachment in order to design appropriate interventions. Only if ICT use is responsible for negative outcomes, measures need to be taken to limit it. Accordingly, we directly compare the common assumption (ICT use as a stressor negatively affecting detachment) with the alternative process (ICT use as a behavioral consequence of lack of detachment and unfinished task; see Fig. 1). Since the situational reasons for ICT use can vary widely, we also consider why employees use their ICTs and examine whether the proposed effects and effect directions differ by type of reason for use (i.e., planned vs. unplanned). To do so, we employ a longitudinal autoregressive design (Finkel, 1995; Zapf et al., 1996) implemented in a diary study.

A second research objective refers to clarifying the nature of work-related ICT use in the evening and impaired detachment. According to boundary theory (Ashforth et al., 2000), it is often difficult for employees to maintain work-life segmentation when ICT is used at home for work purposes (Boswell \& Olson-Buchanan, 2007; Park \& Jex, 2011). We assume that work-related ICT use spills over into leisure time when employees feel an inner and often unconscious desire to complete tasks at home that have been left undone at work. This urge resulting from unfinished tasks, commonly referred to in the literature as the Zeigarnik effect (1938), likely triggers inadequate recovery in the form of poor detachment and increased work-related ICT use in the evening.

Taken together, our study contributes to the literature in three ways: first, our study complements research on workrelated ICT use, which has depicted it as a double-edged sword (e.g., Diaz et al., 2012) or claimed that stress is falsely attributed to ICT (Barley et al., 2011). By examining ICT use in a longitudinal autoregressive diary design, our study is able to ascertain the actual consequences for employees, especially for their after-hours recovery. Second, by investigating behavioral consequences (e.g., dysfunctional recovery activities such as work-related ICT use) of impaired detachment, we expand the stressor-detachment model. Third, by including unfinished tasks as one meaningful work stressor that becomes especially influential when work-life boundaries are transgressed (i.e., work-related ICT is used), we add to research on both the stressor-detachment model and on boundary theory. Methodologically, we contribute by demonstrating how a longitudinal autoregressive model can be implemented in a diary study, answering calls to "make the juice worth the squeeze" (McCormick et al., 2020). Showing how the spillover process unfolds within a working day can 
inspire theorizing about dynamic processes of situational well-being (cf. Sonnentag, 2015).

\section{Negative Consequences of Work-Related ICT Use}

Work-related ICT use refers to all work-related behaviors that are executed with any kind of ICT. Employees spend an increasing amount of time using electronic devices like notebooks, smartphones, and tablets for a wide range of work tasks and to communicate with customers, supervisors, and colleagues (David et al., 2014; Day et al., 2010). The utilization of ICT facilitates work processes, since information is more accessible, tasks can be executed independent from location, and communication in a global workforce is made easier (Day et al., 2010; Diaz et al., 2012). This is why using ICT is often seen as a convenient means to attain goals with maximum flexibility and autonomy. However, this flexibility is accompanied by lots of unwanted side effects, which is why work-related ICT use is not without costs.

An inherent feature of ICT is that it makes the boundaries between work and home more permeable and thereby enables the so-called integration of life domains (Ashforth et al., 2000). By using ICT, employees can, for example, answer client emails during their commute, prepare slides for a presentation from home, and efficiently schedule a meeting with an online tool. Based on the stressor-detachment model (Sonnentag \& Fritz, 2015), it has been frequently argued that work-related ICT use in the evening is a stressor that makes it difficult for employees to detach properly (e.g., Derks et al., 2014b; Ohly \& Latour, 2014). Using ICT for work in leisure time expands the daily working time and thus reduces time for private activities, which keeps employees' strain levels elevated and leads to insufficient recovery and further negative health and well-being outcomes (Sonnentag \& Fritz, 2015). Studies on the relationship between work-related ICT use and detachment have shown that ICT is often used out of necessity, for example, to answer incoming e-mails or to deal with urgent tasks detachment (Barber \& Jenkins, 2014; Derks et al., 2014a; Ohly \& Latour, 2014; Park et al., 2011).

This reasoning fits well with boundary theory (Ashforth et al., 2000), according to which boundary transgressions are more frequent when work-life boundaries are more permeable, which is the case when employees are equipped with ICT. Such boundary transgressions have been shown to impair detachment (Park et al., 2011) and to increase worklife conflict (Boswell \& Olson-Buchanan, 2007; Park \& Jex, 2011). Based on this perspective, studies demonstrated that engaging in work-related ICT use after hours is negatively related to detachment and recovery (Derks et al., 2014a; Ohly \& Latour, 2014; Park et al., 2011), sleep quality (Lanaj et al., 2014), and positively to work-life conflict (Fenner \& Renn, 2010; Wright et al., 2014).

To summarize, based on boundary theory and the stressor-detachment model, the use of ICT for work after hours can be regarded as a factor leading to impaired detachment and reduced well-being (Derks et al., 2014a, 2014b; Lanaj et al., 2014; Ohly \& Latour, 2014), as it represents an actual transition of the work domain into private life. Detachment is not possible when engaging in work-related activities such as ICT use because "it is not sufficient for one to change location by leaving the working place; one must also take a break from thinking about work-related issues" (Sonnentag \& Bayer, 2005, p. 395). In line with previous research, we therefore propose that work-related ICT use early in the evening impedes subsequent detachment.

Hypothesis 1: On days with longer ICT use in the early evening, detachment in the late evening will be lower.

\section{Work-Related ICT Use as a Behavioral Outcome of Impaired Detachment}

While current research mainly classifies working via ICT as a dysfunctional stressor that makes detachment less likely (Duranová \& Ohly, 2016), it can also be regarded as a behavior employees fall back on to deal with a high workload, to finish a nagging task, or to solve a problem that occupies their mind. From this perspective, the inability to fully detach from work plays a key role, as it stimulates to engage in work-related behaviors such as work-related ICT use. Properly detaching from work is central to the recovery process, but it can be difficult when an employee has been exposed to a high level of work stressors (e.g., time pressure, high workload, or many unfinished tasks) during the workday (Berset et al., 2011; Sonnentag \& Bayer, 2005). ICT might therefore be used for work when employees' minds are occupied with work-related thoughts anyway. Albeit, not being able to detach from work has been shown to negatively relate to well-being and health in numerous cross-sectional and longitudinal studies (for reviews, see Bennett et al., 2018; Sonnentag \& Fritz, 2015; Wendsche \& Lohmann-Haislah, 2017). The availability of ICT can facilitate work-related activities, such as answering emails, as it provides location-independent access to work-related information that would otherwise be unavailable (Park et al., 2011; Sonnentag, 2001).

Thus, we conclude that employees are likely to use ICT to deal with work tasks that have made detachment difficult. For example, employees who are confronted with a tight deadline at work might know that they will be unable to switch off from work during the evening. They might then use ICT to finish certain tasks, to jot down a few ideas, to get an overview 
over topics that need to be discussed the next day, or just to cope with the inner states (such as worry or rumination) that accompany unsuccessful detachment and often become salient through signals about incoming messages (Heitmayer \& Lahlou, 2021).

Although the notion that work-related ICT use is itself a consequence of impaired detachment has been mostly unexplored, some qualitative studies revealed that employees use ICT to respond to work-related demands in a convenient way (Matusik \& Mickel, 2011) or to cope with work demands (Barley et al., 2011). As far as quantitative studies are concerned, Ohly and Latour (2014) showed that a long duration of workrelated ICT use can be detrimental, but not the use per se. They concluded that the use of ICT might be a helpful strategy to enhance detachment, for example, by helping employees to complete tasks. Based on the qualitative research findings and this line of reasoning, we propose that ICT is used longer late in the evening when detachment is impaired.

Hypothesis 1: On days when employees are less able to detach from work in the early evening, ICT use in the late evening will be longer.

\section{Individual Reasons for Work-Related ICT Use}

As briefly outlined above, the reasons why people reach for their devices in their free time to continue working can be manifold (Matusik \& Mickel, 2011; see also Ohly \& Latour, 2014). Based on our theoretical considerations, we do not assume that the proposed mechanisms and effects regarding detachment differ by situational cause of ICT use. However, to ensure that the proposed effects can be generalized across various occasions, we test our model for both planned and unplanned work-related ICT use and thus provide evidence for the robustness of effects. We refer to planned ICT use in cases where individuals thought about using the device beforehand, which means that there was a clear intention to do so during leisure time. However, ICT use is also often elicited by external, person-independent signals about incoming messages (Heitmayer \& Lahlou, 2021), by other situational cues or inner states not directly related to work issues (such as worry or boredom). In these cases, ICT use is less intentional and deliberate, but rather an immediate reaction to situational cues (responding to auditory or visual cues to fill idle time) or internal states, which is why we refer to this as unplanned ICT use.

\section{The Role of Finishing Work Tasks}

Boundary theory suggests that spillover between work and private life can be positive or negative, depending on what is transferred from one life domain to the other. Not being able to finish all work tasks is a common experience in modern work life. According to Syrek et al., (2017, p. 227), unfinished tasks "refer to tasks that the employee aimed to finish (or make certain progress [on]), but which were left undone (or left in an unsatisfactory state) when the employee stopped working." When employees have to leave unfinished work tasks behind, they are more likely to be mentally occupied with work when they come home (Syrek \& Antoni, 2014; Syrek et al., 2017). In a series of studies, Syrek and collaborator demonstrated the validity of this concept: in four independent studies, unfinished tasks assessed on Friday were related to rumination over the course of the weekend that was reported on Monday (Syrek \& Antoni, 2014; Syrek et al., 2017; Weigelt \& Syrek, 2017). The effect is also negative and significant when performance expectations are low (Syrek \& Antoni, 2014). Moreover, progress on unfinished tasks buffered the negative effect of unfinished tasks on detachment (Weigelt \& Syrek, 2017). In addition, unfinished tasks seem to impair flow experiences (Peifer et al., 2020).

We argue, based on boundary theory (Kreiner et al., 2009), that one reason why work-related ICT use in the evening is associated with impaired well-being is because it is often a consequence of unfinished tasks. In other words, the true source of impaired well-being are the unfinished tasks which spill over into the home domain via the use of ICT. According to that, bringing job demands or stressful experiences at work into the home domain might pronounce the effects of these job stressors, which leads to rumination and impaired sleep (Sonnentag \& Kruel, 2006; Syrek \& Antoni, 2014; Syrek et al., 2017). Thus, ICT use is a tool that enables bringing home tasks, and working after hours: When employees are unable to finish their tasks, they find it difficult to disengage from work-related thoughts and cannot properly engage in recovery activities (Syrek \& Antoni, 2014; Syrek et al., 2017; Weigelt \& Syrek, 2017). Instead, employees are likely to engage in various work-related activities including work-related ICT use, which is why we consider it a behavioral consequence of facing unfinished work tasks. In summary, we thus expect:

Hypothesis 3a: On days with more unfinished tasks after work, the level of detachment in the evening will be lower.

Hypothesis 3b: On days with more unfinished tasks after work, work-related ICT usage in the evening will be longer.

When facing unfinished tasks, engaging in work-related activities might not necessarily impact recovery and wellbeing beyond the negative impact of reduced detachment. A qualitative study by Barley et al. (2011) even concluded that employees could increase their ability to cope with 
job demands by using e-mail. Additionally, Weigelt and Syrek (2017) showed that making progress on unfinished tasks over the weekend by doing supplemental work alleviates some of the detrimental effects of unfinished tasks, as it removes the stressor and fulfills a need for closure. Therefore, we argue that in situations in which employees are confronted with unfinished work tasks, they can benefit from work-related ICT use after hours by making progress on or complete unfinished work tasks. Accordingly, we propose that on days when employees have to deal with a high level of unfinished tasks when finishing their work day, they will use work-related ICT more which relates to higher task progress in the late evening.

Hypothesis 4a: On evenings where individuals engage in longer work-related ICT use, they will make more progress on unfinished work tasks.

Hypothesis $4 \mathrm{~b}$ : On evenings where individuals report higher detachment, they will make less progress on unfinished work tasks.

\section{Method}

\section{Procedure and Participants}

We commissioned a German market research company to invite members who (a) qualified as knowledge workers, (b) were full-time employees (at least $30 \mathrm{~h} /$ per week), (c) were not on vacation for the 2 weeks prior to the diary study, (d) were equipped with any ICT (e.g., smartphone and notebook) by their employer, and (e) owned an additional private smartphone. Upon agreement with the company prior to data collection, complete data should be collected from at least 150 people within 4-6 weeks in order to be able to detect even small effects. Considering the usual dropout rates in diary studies of about $50 \%$, a sample of 300-350 people should therefore be invited (oversampling). There was no additional data collection commissioned by us.

Using separate devices for work and responding to the daily diary was a necessary precondition, as using the same device to answer questionnaires and for work would potentially create biases in the assessment of ICT use (e.g., by evoking work-related thoughts or by drawing attention to notifications about incoming work requests). The invited individuals first received a letter outlining the purpose of the study, detailing the requirements, and assuring the anonymity and confidentiality of all responses. The letter also contained instructions on how to participate. Volunteer participants filled out a screening questionnaire to assure they met the requirements. Eligible participants then completed a general online survey with background information.
Participants were asked to fill out three daily surveys over the course of five business days (15 daily surveys in total). They were instructed to fill out the first daily questionnaire when they were finishing up work (T0) to assess if there were any work tasks they left unfinished. Then, they received the subsequent daily surveys $90 \mathrm{~min}$ (T1) and $180 \mathrm{~min}$ (T2) after the first daily survey. Notifications to fill out surveys were sent via a smartphone application. Participation could be delayed for a maximum of $60 \mathrm{~min}$, which delayed the notification for the following survey by the same amount of time. We chose these time lags because a standard work day in Germany ends between 4 p.m. and 6 p.m. (Indeed, 2016), so that the late evening survey (T2) was completed a maximum of $5 \mathrm{~h}$ later between 9 p.m. and 11 p.m. On average, the time lag between the T0 and the T1 questionnaire was $104.29 \min (S D=14.92)$; a similar time lag emerged for T1 and T2 $(M=101.91, S D=12.89)$. As a reward for participating and to prevent dropout, participants received a compensation of $35 €$ if they completed the general and 12 out of the 15 daily questionnaires (80.0\%). Of the 435 individuals who originally agreed to participate in the study, 340 responded to at least one daily survey (78.2\%), 246 (72.4\%) completed all three daily surveys on at least one day, 211 (48.0\%) fulfilled the requirements for a compensation, and 199 participants completed all 15 questionnaires (called finishers below). From the 340 individuals who comprised our final sample, we received 3284 individual survey responses in the course of the 5-day study, which could be assigned to 1289 within-level cases (i.e., days).

As we had a diary study with a longitudinal autoregressive model at the within-person level, two types of participant attrition need to be analyzed to ensure that there is neither a selective participation in the course of the study nor in the course of daily assessments. First, we tested in the final sample whether people who responded every day $(n=199)$ differed from those who did not participate on all 5 days $(n=141)$. For demographic variables, $t$ test results revealed no differences for age $(p=0.706)$, gender $(p=0.787)$, leadership status $(p=0.535)$, work tenure $(p=0.942)$, time spent in company $(p=0.674)$, time spent in current position ( $p=0.280)$, average daily working hours $(p=0.937)$, and average weekly working hours from home $(p=0.136)$. For the main study variables, daily mean values were aggregated to perform independent $t$ tests. The results showed no differences between the two groups for detachment (T1: $p=0.308$; $\mathrm{T} 2: p=0.236)$, ICT use (T1: $p=0.481 ; \mathrm{T} 2: p=0.791)$, and task progress (T1: $p=0.102$; T2: $p=0.378)$. However, $t$ test was significant for unfinished tasks $(p=0.001)$ and indicated that individuals who did not participate each day reported an average of more unfinished tasks, but the effect size was rather small (Cohen's $d=0.42$ ).

Next, attrition was analyzed at the day level using simple within-level logistic regressions with group mean-centered 
data. The results indicated that participant dropout in the evening (i.e., individuals who did not complete all surveys in a day) was not predicted by unfinished tasks $(p=0.710)$, detachment (T1: $p=0.328$; T2: $p=0.229$ ), ICT use (T1: $p=0.259$; T2: $p=0.318$ ), and task progress (T1: $p=0.922$; $\mathrm{T} 2: p=0.648)$. Regarding demographic variables, the logistic multilevel regressions with uncentered data revealed no effect for age $(p=0.128)$, gender $(p=0.397)$, leadership status $(p=0.168)$, work tenure $(p=0.494)$, time spent in company $(p=0.515)$, time spent in current position $(p=0.174)$, and average daily working hours $(p=0.178)$. However, we found that leaders were less likely $(\mathrm{OR}=0.49, p=0.025)$ and participants with higher average weekly working hours from home $(\mathrm{OR}=0.94, p=0.015)$ slightly more likely to complete all daily surveys. But such between-person differences were ruled out by group mean-centering (see explanation below). Taken together, the data was not significantly biased by respondent attrition, which is why we considered all 340 individuals for hypothesis testing using a full information maximum likelihood estimation, which is recommended for incomplete data (FIML; Raykov, 2005). To cross-check a potential bias of the results due to the significant differences for unfinished tasks, we compared a model that only included finishers $(n=199)$ with the model based on the final sample. The effects of the finisher model showed only marginal differences in the second decimal place, providing evidence for the robustness of the FIML-based results.

The final sample consisted of 340 German knowledge workers from a wide range of industries and professions, such as marketing, consulting, management, and research. Participants usually occupied more high-level positions with $76.2 \%$ holding a leadership position. Slightly more than half $(52.6 \%)$ of our sample was male. Mean age of participants was 39.74 years $(S D=10.23)$. In total, $3.2 \%$ of the sample had a doctoral degree, $43.8 \%$ had a university degree, $26.8 \%$ had a high school degree, $23.8 \%$ had a middle school degree, and $1.5 \%$ had a general education secondary school degree. On average, participants had 18.28 years of work experience $(S D=10.69)$, and they had been working at their current company on average for 9.91 years $(S D=7.96)$. Average job tenure was 6.06 years $(S D=5.12)$ and average hours worked per day was 8.55 $(S D=0.93)$. Most participants were equipped with a notebook (79.4\%) and/or a smartphone (72.1\%). Additionally, $36.8 \%$ of participants were equipped with a tablet. An overview of the descriptive statistics for the different occupational classes in our sample is shown in Table 1. There were small differences between occupations for unfinished tasks, detachment ( $\mathrm{T} 1$ and $\mathrm{T} 2$ ), and task progress ( $\mathrm{T} 1$ and T2). For ICT use, by contrast, the mean usage time differed considerably between occupations (Table 1), but standard deviations in each occupation were also large, indicating high variability.

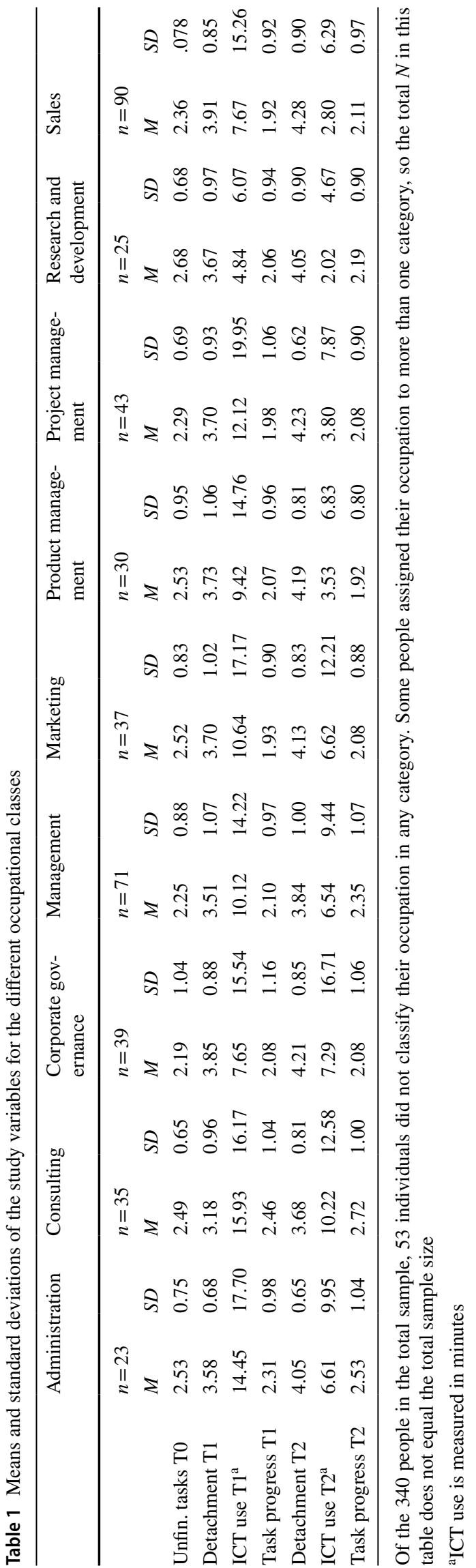


Table 2 Means, standard deviations, internal consistencies, and intercorrelations among study variables

\begin{tabular}{|c|c|c|c|c|c|c|c|c|c|c|}
\hline & Variable & $M$ & $S D$ & 1 & 2 & 3 & 4 & 5 & 6 & 7 \\
\hline 1 & Unfinished tasks T0 & 2.26 & 0.97 & $(.87)$ & $-.48 * * *$ & .16 & $.30 * * *$ & $-.56 * * *$ & $.19 *$ & $.35 * * *$ \\
\hline 2 & Detachment T1 & 3.62 & 1.28 & $-.20 * * *$ & $(.91)$ & $-.72 * * *$ & $-.53 * * *$ & $.89 * * *$ & $-.62 * * *$ & $-.49 * * *$ \\
\hline 3 & ICT use $T 1^{\mathrm{a}}$ & 10.40 & 18.49 & $.20 * * *$ & $-.49 * * *$ & - & $.66^{* * *}$ & $-.58 * * *$ & $.88 * * *$ & $.63 * * *$ \\
\hline 4 & Task progress $\mathrm{T} 1$ & 2.11 & 1.25 & $.24 * * *$ & $-.39 * * *$ & $.48 * * *$ & $(.87)$ & $-.43 * * *$ & $.54 * * *$ & $.92 * * *$ \\
\hline 5 & Detachment T2 & 4.12 & 1.10 & $-.13 * * *$ & $.36 * * *$ & $-.17 * * *$ & $-.14 * * *$ & $(.91)$ & $-.68 * * *$ & $-.44 * * *$ \\
\hline 6 & ICT use $\mathrm{T} 2^{\mathrm{a}}$ & 5.40 & 13.86 & $.11^{* *}$ & $-.18 * * *$ & $.25 * * *$ & $.19 * *$ & $-.47 * * *$ & - & $.52 * * *$ \\
\hline 7 & Task progress $\mathrm{T} 2$ & 2.30 & 1.31 & $.20 * * *$ & $-.29 * * *$ & $.32 * * *$ & $.51 * * *$ & $-.27 * * *$ & $.25 * * *$ & $(.86)$ \\
\hline
\end{tabular}

Correlations below the diagonal represent the within-person level $(k=1289)$. Correlations above the diagonal represent the between-person level $(N=340)$. Within-level McDonald's omega in parentheses. T0 $=$ Time $0 ; \mathrm{T} 1=$ Time $1 ; \mathrm{T} 2=$ Time 2

${ }^{\mathrm{a}} \mathrm{ICT}$ use is measured in minutes, but logarithmized for the correlations

${ }^{*} p<.05$. ** $p<.01 . * * * p<.001$ (two-tailed)

\section{Measures}

Consistent with the recommendations by Ohly et al. (2010), we used abbreviated scales to reduce burden on our participants and enhance compliance. Internal consistency was estimated using coefficient omega proposed by McDonald (1999). Unlike Cronbach's alpha, omega does not assume tau-equivalence, uncorrelated residuals, and the same size of item variance. Since these assumptions are often not fulfilled by field data (Yang \& Green, 2011), it was recommended to take omega instead of alpha (Dunn et al., 2014). To do so, within-level confirmatory factor analyses were performed, with items centered around the group mean to remove between-level variance. Table 2 displays the scale means, standard deviations, reliabilities, and correlations among our study variables.

Detachment We adapted three items from the four-item scale developed by Sonnentag and Fritz (2007) to refer to detachment during the timespan between measurement points. A sample item is "In the time that has passed since answering the last questionnaire, I forgot about work" $(1=$ strongly disagree and $5=$ strongly agree $)$. To shorten the scale, we excluded the fourth item ("I get a break from the demands of work") which had the lowest loading on the detachment factor in the study by Sonnentag and Fritz. The internal reliability of our shortened scale was $\omega=0.91$ for $\mathrm{T} 1$ and $\omega=0.91$ for $\mathrm{T} 2$.

ICT Use We asked participants to estimate the duration of their ICT use for work in the timespan between measurement points using the following item: "In the time that has passed since answering the last questionnaire, how long did you use new technologies (e.g., smartphone, computer, tablet) for work?" Participants estimated this duration in minutes. If they indicated that they did not use ICT, we coded the length of ICT use as zero minutes. As a result, the distribution of
ICT use was skewed (i.e., had a floor effect), which violates the normal distribution requirement of maximum likelihood (ML) estimation. For this reason, we log transformed the variable (logarithmus naturalis) for hypothesis testing in order to approximate a normal distribution (e.g., Rasmussen \& Dunlap, 1991). However, since the logarithm of zero is not defined, we replaced it with a small value $(0.3)$ to avoid having to code the data as missing. In result of this procedure, the absolute variance was reduced and better fitted to the variances of the other variables, helping to better reproduce the empirical covariance matrix in structural equation modeling.

Reasons for ICT Use To assess why individuals used their devices in the evening, we asked participants at T1 and T2 to indicate for what reason they used ICTs in the preceding hours. They were given five options based on previous literature (e.g., Braukmann et al., 2018; see also Fig. 3), plus "other." Participants were allowed to tick more than one reason.

Unfinished Tasks We measured unfinished tasks at the end of the workday before participants left the workplace (T0) with three out of six items from a scale developed by Syrek et al. (2017) that we adapted to refer to the day level. Participants responded on a rating scale ranging from 1 (strongly disagree) to 5 (strongly agree). A sample item for this scale is "I have not finished important tasks that I had planned to do today." McDonald's omega was $\omega=0.77$. We excluded the three items that were not suitable for assessing unfinished tasks on a day level (e.g., "I have not finished a large amount of due tasks this week.").

Task Progress We took two items from the scale by Syrek et al. (2017) that measure unfinished tasks and adapted the item formulation so that they indicate task progress. Participants responded on a rating scale ranging from 1 (strongly 
Table 3 Variance composition of study variables

\begin{tabular}{llll}
\hline Variable & $\begin{array}{l}\text { Within-individual vari- } \\
\text { ance }\left(e^{2}\right)\end{array}$ & $\begin{array}{l}\text { Between-individual vari- } \\
\text { ance }\left(r^{2}\right)\end{array}$ & $\begin{array}{l}\text { Percentage of } \\
\text { within-individual } \\
\text { variance }\end{array}$ \\
\hline Unfinished tasks T0 $^{2}$ & 0.54 & 0.41 & 56.84 \\
Detachment T1 $_{\text {ICT use T1 }}^{\text {a }}$ & 0.99 & 0.62 & 61.49 \\
Task progress T1 $_{\text {Detachment T2 }}$ & 4.14 & 2.71 & 60.44 \\
ICT use T2 $^{\text {a }}$ & 0.85 & 0.72 & 54.14 \\
Task progress T2 & 0.71 & 0.49 & 59.17 \\
\hline
\end{tabular}

$e^{2}$ represents the within-person variance and, $r^{2}$ the between-person variance

${ }^{\mathrm{a}}$ ICT use is measured in minutes, but logarithmized for the calculation disagree) to 5 (strongly agree). The two items were "I have finished important tasks that I had planned to do today but was not able to finish during work hours" and "I have made progress on important work tasks." Internal consistency was $\omega=0.87$ for $\mathrm{T} 1$ and $\omega=0.86$ for $\mathrm{T} 2$.

\section{Preliminary Analyses}

Since detachment, ICT use, and task progress were assessed twice a day for one working week, we had a longitudinal autoregressive diary design with a hierarchical data structure (i.e., repeated measures nested within individuals). This method requires three preparatory steps before the hypotheses can be tested properly: (1) determining whether the within-level variance is sufficient to test the within-level effects (Hox, 2002), (2) establishing measurement invariance across time (Finkel, 1995), and (3) testing the appropriateness of measurements using multilevel confirmatory factor analysis (MCFA). To obtain the within-person variance, we ran null models using the Mplus software version 8.4 (Muthén \& Muthén, 1998-2017). The analysis revealed significant within-person variance for all variables (see Table 3).

The levels of invariance were analyzed with nested MCFAs that included detachment and task progress at both waves (Little et al., 2007). As ICT use was measured with a single item, it was not considered here. The results confirmed strong factorial invariance. At the level of strict factorial invariance (i.e., residual invariance), the results showed that two items measuring detachment had different residual variances over time and were therefore allowed to vary (Table 4$)$. This significantly improved the model fit, but the chi-square difference was still significant. Nevertheless, we decided to analyze the data on the basis of Model IN4 (see Table 4), as the overall fit was good and no single parameter was responsible for the significant model difference. Lastly, we performed an MCFA with all variables at both levels of analysis to provide evidence for the construct validity. Overall, the seven-factor model showed a good fit to the data $\left(\chi^{2}=230.66, d f=159, p<0.001\right.$, $\chi^{2} / d f=1.45$; Root Mean Square Error of Approximation RMSEA $=0.019$; Standardized Root Mean Square Residual SRMR $_{\text {WITHIN }}=0.023$ and SRMR BETWEEN $=0.034$; Comparative Fit Index CFI=0.994).

\section{Analytical Strategy}

Accounting for the hierarchical data structure, we performed multilevel structural equation modeling (MSEM) in Mplus 8.4 to test the proposed effects. Prior to hypothesis testing, descriptive statistics were calculated (Table 2). The bivariate correlations of all variables were calculated based on latent decomposition (Muthén \& Muthén, 1998-2017; see also Preacher et al., 2016), which means that they were partitioned into two latent parts, one that varies only within persons and one that varies only between persons. This procedure provides unbiased estimates of the within- and between-level relationships.

For hypothesis testing, unfinished tasks, detachment, and task progress were treated as latent constructs with items as indicators. We set free one (and of course the same) residual covariance for detachment at both waves because the wording of the corresponding two items was similar (cf. Kam $\&$ Fan, 2020). ICT use was also modeled as a latent variable with a single indicator, as this supports the analysis of complex structural models and strengthens the confirmatory nature of analysis. Hayduk and Littvay (2012) and Petrescu (2013) convincingly argued that a single item is appropriate when the latent construct is simple and unidimensional and as long as measurement error can be considered small. As measurement models with one indicator are not identified, we set the factor loading to 1 and the residual variance to 0.01 , assuming that the reliability of ICT use is almost perfect (as one would do in the case of manifest variables). Beyond our hypotheses, we allowed a correlation between 


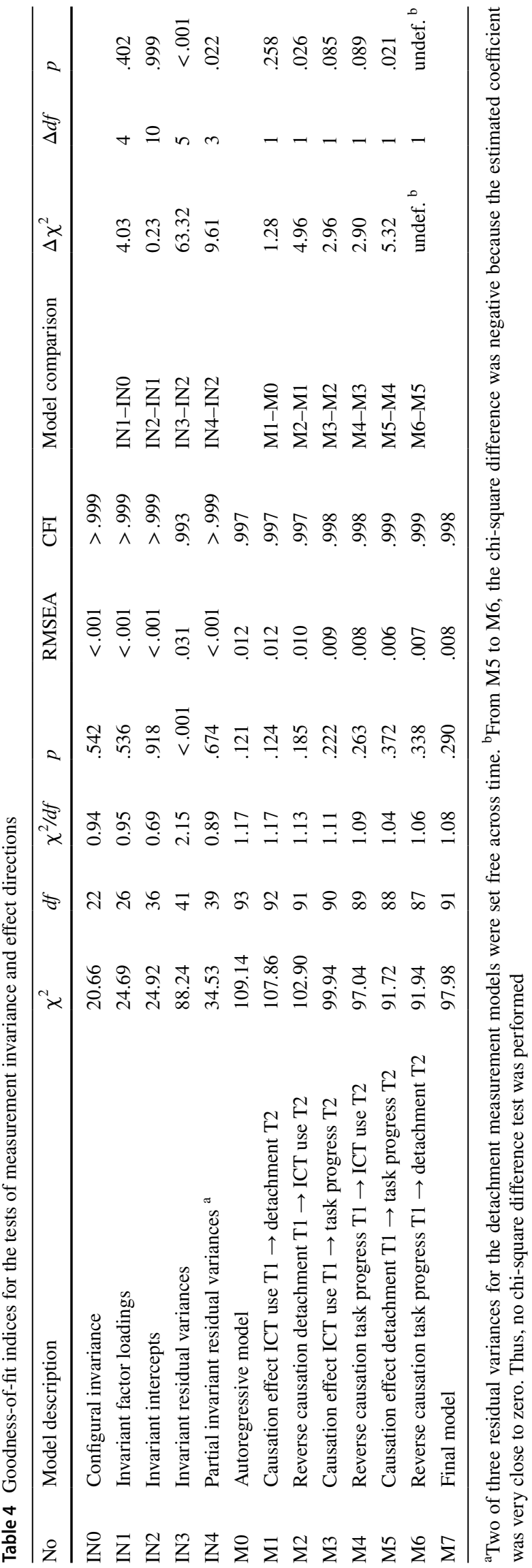

unfinished tasks at $\mathrm{T} 0$ and task progress at $\mathrm{T} 1$, since it is implausible that both variables are unrelated.

Since the study hypotheses pertain to the within-level, all variables were centered around each person's mean in order to rule out between-person effects. Doing so, all types of between-person differences, such as demographics, segmentation preferences, attitudes towards ICT use, personality, between-person level ICT use, between-person level detachment, etc. are statistically controlled for. Accordingly, structural models were only built at the within-level of analysis. However, we also modeled the final model M7 on both levels simultaneously (i.e., full specification of all measurement models and structural paths on both levels without groupmean centering of the variables) to see if there were different results in our model on the between-person level. ${ }^{1}$

A series of competing structural models were calculated to test the direction of causal effects (cf. Zapf et al., 1996). We started the analysis with an autoregressive model that included residual covariances between the corresponding $\mathrm{T} 1$ and $\mathrm{T} 2$ items and synchronous correlations among the latent constructs (M0). We then examined the causal direction with hierarchical structural models, which always estimated one more parameter (i.e., an additional causal or reversed causal effect between the variables; see Models M1-M6 in Table 4). The final model M7 only considered effects that were found to significantly increase model fit in model comparisons. The goodness-of-fit statistics of all models are shown in Table 4.

To test the robustness of the results, we tested whether the postulated within-level effects depended on the reason for employees' ICT use in the early evening. In particular, we were interested in differences between planned and unplanned ICT use. We therefore analyzed the final model again on the basis of (1) all responses where employees indicated planned ICT use at T1 $(N=103 ; k=160)$ and compared the results to a model (2) where employees used their ICTs for other reasons (i.e., unplanned; $N=335 ; k=593$ ).

We report fully standardized results. Model fit was assessed using chi-square statistics. A non-significant chisquare value indicates a good fit to the empirical covariance matrix (Schermelleh-Engel et al., 2003). In addition, two descriptive fit indicators were used: (1) the RMSEA and (2) the CFI. As recommended by Schermelleh-Engel et al. (2003), values less than 0.05 for RMSEA and values of 0.97 or higher represent a good fit.

\footnotetext{
1 We would like to thank the anonymous reviewer for the idea of analyzing the model at the between-person level as well.
} 


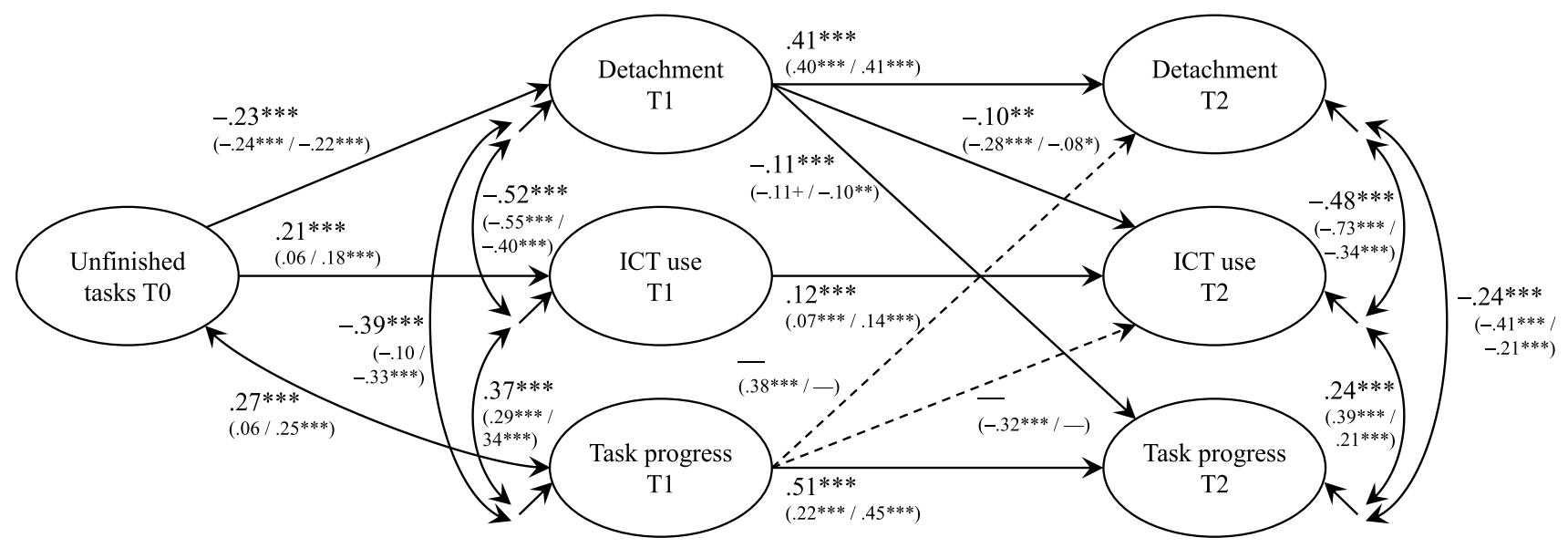

Fig. 2 Results of the within-person cross-lagged panel. Coefficients in parentheses refer to subgroup analyses, where the first coefficient represents the results for planned ICT use and the second coefficient the results for unplanned ICT use (all other reasons). Dashed lines refer to paths that were only significant for planned ICT use and were thus only modeled here (confirmed by significant chi-square difference tests). ${ }^{*} p<.05 .{ }^{*} p<.01 . * * * p<.001$ (one-tailed)

\section{Results}

Figure 2 shows the final model (M7) including all significant effects. As shown in Table 4, the model fitted the data well. Hypothesis 1 expected a positive cross-lagged effect of ICT use on detachment. However, the chi-square value did not significantly improve from the autoregressive model, pointing to no such lagged effect (Table 4). Thus, Hypothesis 1 was not supported. In contrast, the chi-square difference was significant for the model including a reverse causal effect of detachment on ICT use (M2, see Table 4), supporting Hypothesis 2. Although the effect was small, the results shown in Fig. 2 demonstrate that on days when individuals are less able to detach from work, they spend more time using ICT for work. Of note, the within-person cross-sectional relationships between detachment and ICT use for work $(-0.51$ at $\mathrm{T} 1$ and -0.48 at $\mathrm{T} 2)$ were consistent with the negative relationships in previous studies (e.g., Derks et al., 2014a, 2014b; Eichberger et al., 2020).

In Hypothesis 3, we considered the influence of unfinished tasks at the end of the work day. The results presented in Fig. 2 show that unfinished task significantly predicted detachment and ICT use in the early evening, which supports $\mathrm{H} 3 \mathrm{a}$ and $\mathrm{b}$. Finally, Hypothesis 4 posited that more ICT use (4a) and lower detachment (4b) lead to higher task progress in the late evening. Conflicting with expectations of H4a, Model M3 revealed no better fit, which points to a non-significant lagged effect of ICT use on task progress (Table 4). In support of Hypothesis $4 \mathrm{~b}$, however, model comparisons preferred the model containing a lagged effect of detachment $\mathrm{T} 1$ on task progress T2 (Model M5), albeit the effect was small in size. When individuals were less able to detach they reported higher progress in the late evening. Thus, Hypothesis 4 was partially confirmed.

\section{Reasons for ICT Use and Related Differences in the Longitudinal Autoregressive Model}

The most frequent reasons for ICT use in the early and late evening were "signal about incoming message" (32.2\% at $\mathrm{T} 1$ and $31.4 \%$ at $\mathrm{T} 2)$, "work was on my mind" (27.1\% and $28.1 \%)$, and "planned use" (21.5\% and $18.8 \%$; see also Fig. 3). "Worry that I have missed an important message" (14.0\% and $15.2 \%)$ and "distraction to fill time" (5.2\% and $6.4 \%$ ) were indicated less frequently as reasons why participants used ICT for work-related purposes. Only few participants (1.3\% and $2.6 \%)$ indicated other reasons for using their ICTs such as responding to emergencies, all of which represented unplanned ICT use for work. These results suggest that work-related ICT use in the evening is mainly driven by interruptions, supporting earlier work on the prevalence of notifications (e.g., Heitmayer \& Lahlou, 2021) and preoccupation (i.e., work was on my mind), both of which represent unplanned ICT use, or by a preset goal in a strategic way (planned use).

The comparison of the two subgroups of days (planned vs. unplanned ICT use; see Fig. 2) revealed that the causal effect of detachment on ICT use and task progress is generalizable to all reasons for ICT use. Three interesting differences in findings emerged: the negative effect of detachment on ICT use in the late evening was even stronger when employees indicated that they planned to use ICTs at T1. Note, however, that this difference was statistically not significant $(\Delta[\beta / S E]=1.45 ; p=0.147)$. In addition, a positive lagged effect of task progress on detachment and a negative 
Fig. 3 Reasons for ICT use in the evening. The vertical axis represents the number of withinlevel responses. Both at $T 1$ and T2, 10 people reported other reasons for ICT use than shown in the figure

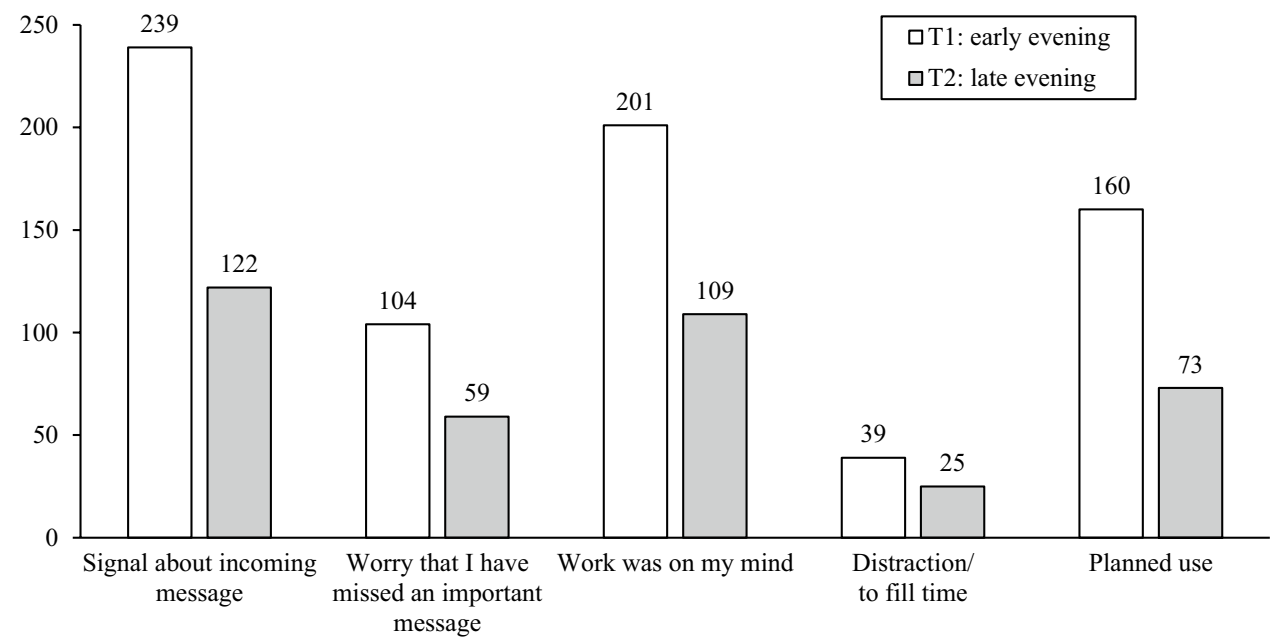

one on ICT use was found in cases where employees used ICTs in a planned manner, but not when they used their ICTs in response. Finally, unfinished tasks did not predict ICT use in the early evening when employees planned to use them after work.

\section{Between-Level Effects and Robustness of the Within-Level Model}

To ensure that our analyses did not hide or artificially produce significant effects, we also analyzed the proposed model at the between-person model while controlling for within-level effects. The results presented in Fig. 4 showed that the within-person effects did not differ from model M7, indicating robustness of our analytical procedure. Moreover, the between-level results showed very high autoregressive effects $(>0.90)$ and thus made an interpretation difficult, with one exception. In the case of planned use, the autoregressive effect of ICT use was of medium size $(\beta=0.47$, $S E=0.09$ ), which allows for the interpretation of the crosslagged effect of ICT use T1 on detachment T2. The negative effect ( $\beta=-0.47, S E=0.25$ ) suggests that individuals who use ICT for work in the evening and planned to do so are less able to detach later in the evening. Notably, this is in contrast to the within-person results that revealed no detrimental effect of ICT use (as described above), even for planned use.

\section{Discussion}

The main purpose of this study was to test and evaluate the directions of effects between ICT use for work after hours, psychological detachment, and task progress, as well as to identify the role of unfinished tasks on work-related ICT use and detachment during leisure time. We employed a longitudinal autoregressive model within a diary study to allow for an investigation of causal effects. Contrary to our expectations, Hypothesis 1, stating that work-related ICT use in the early evening results in less detachment in the late evening, was not supported. The daily length of work-related ICT use at T1 did not reduce detachment at T2. Instead, our results supported Hypothesis 2: low detachment in the early evening was related to longer work-related ICT use in the late evening, regardless of the reason employees began using their ICTs. Although the effect was rather small and particularly smaller compared to previous studies that have relied on cross-sectional relationships (i.e., have not controlled for autoregressive effects), one should consider that effect sizes in longitudinal analyses are often greatly smaller than in cross-sectional analyses (Adachi \& Willoughby, 2015). We would therefore like to caution that a small effect does not necessarily point to a trivial effect and should not be directly compared with analyses that neglect autoregressive effects. Moreover, it is implausible to expect higher effects given the small time span of $90 \mathrm{~min}$ in which a significant change can have occurred (cf. Frese \& Zapf, 1988).

Consistent with Hypothesis H3, we found that unfinished tasks after leaving work positively predicted ICT use and negatively predicted detachment early in the evening. Together with the positive correlation between unfinished tasks and task progress, this finding supports the notion that unfinished tasks at the end of the work day are a driving force for maintaining work-related activities in the evening. Finally, Hypothesis 4b, but not $4 a$, was supported. Engaging in work-related ICT use early in the evening showed no lagged effect on task progress later in the evening. This result may indicate that employees are not capable of handling larger tasks through the use of ICT. However, since we consistently found cross-sectional correlations both early and late in the evening, ICT use could be linked to the fulfillment of smaller tasks that only required brief consideration. Supporting H4b, a higher level of detachment at T1 showed 


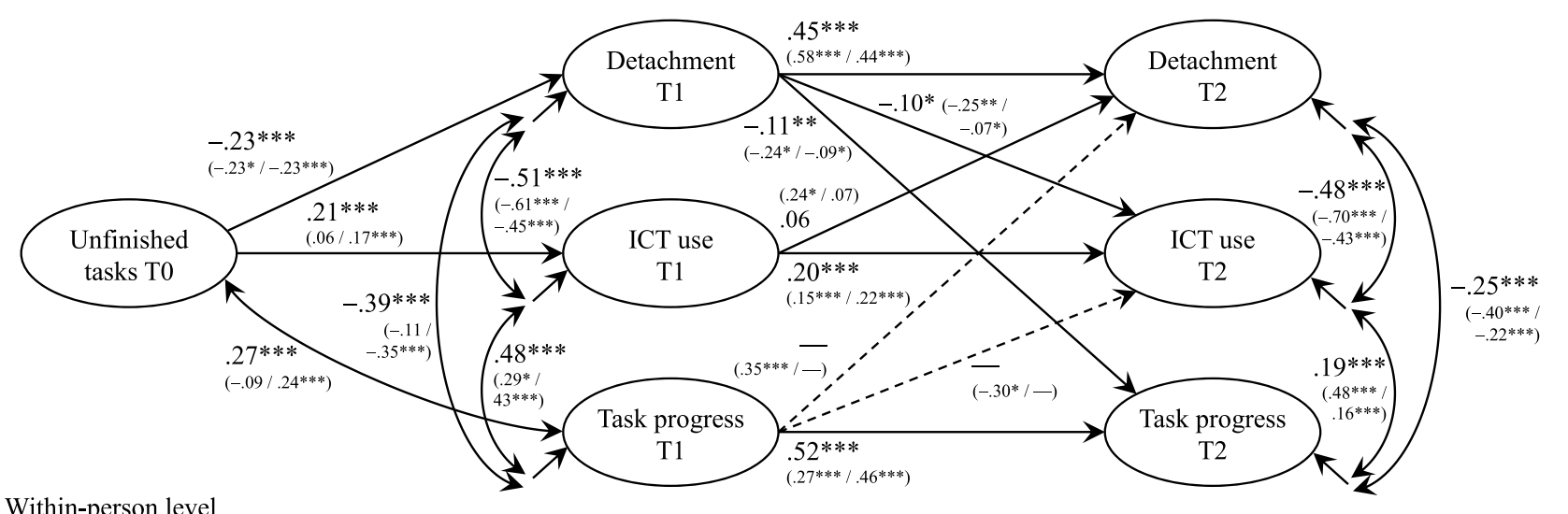

Within-person level

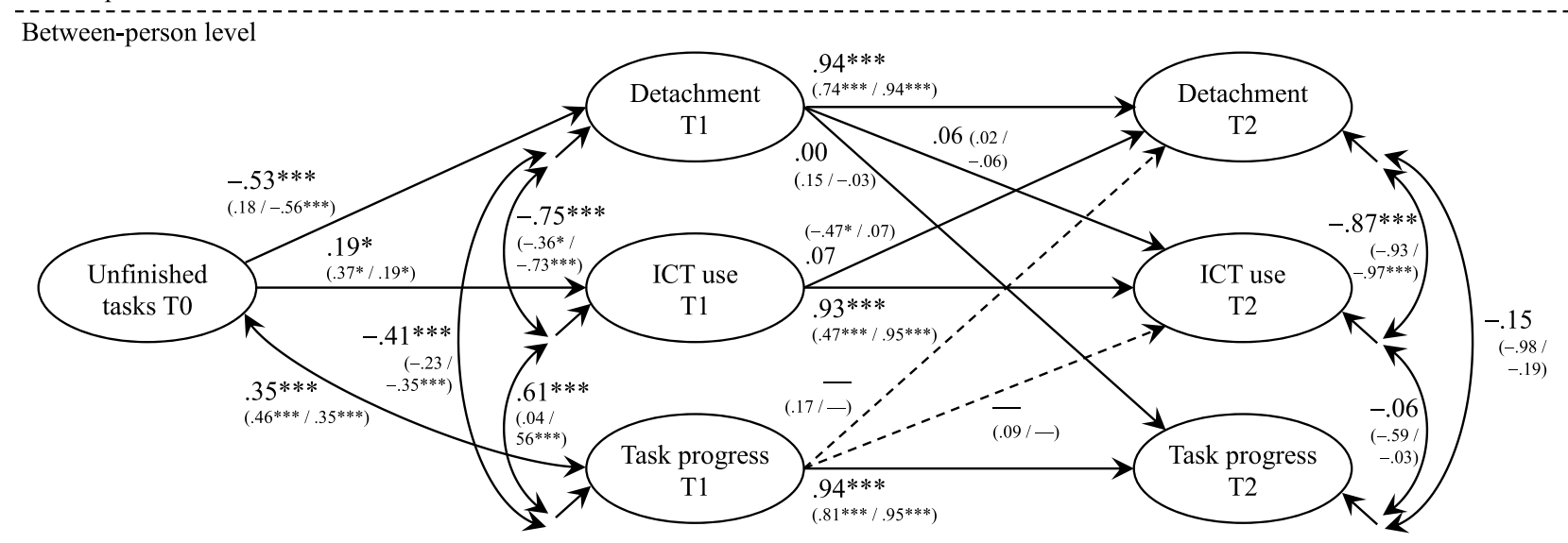

Fig. 4 Results of the multilevel cross-lagged panel. Coefficients in parentheses refer to subgroup analyses, where the first coefficient represents the results for planned ICT use and the second coefficient the

a significant negative lagged effect on task progress at T2, suggesting that on days when employees are less able to properly detach from work, they either actually make progress on tasks that buzz in their minds after a day's work, or at least perceive that they are doing so (cf. Syrek \& Antoni, 2014).

\section{Theoretical Implications}

The present findings are more consistent with the notion that the daily level of unfinished tasks impairs detachment, which in turn prompts employees to engage in work-related ICT use and to make progress on these tasks. From this perspective, employees engage in work-related behavior more on days when they have to cope with more unfinished tasks and find themselves unable to detach from work. Our study supports the view that stress responses are often falsely attributed to ICT use (Barley et al., 2011) and corroborates earlier findings from qualitative studies (Matusik \& Mickel, 2011) that ICT use is a way of dealing with high job demands. Moreover, our findings suggest that previous studies linking ICT use and low well-being or lack of detachment might results for unplanned ICT use. Dashed lines refer to paths that were only significant for planned ICT use. ${ }^{*} p<.05$. ** $p<.01$. $* * * p<.001$ (one-tailed)

have confounded the behavior with its cause, namely, the level of unfinished tasks or other work stressors.

Although we did not identify ICT use as a stressor in its own right in line with the stressor-detachment model (Sonnentag \& Fritz, 2007, 2015; Sonnentag et al., 2017), this study nevertheless supported the model by showing that unfinished tasks as a stressor lead to lower detachment. In addition, our study extends the stressor-detachment model by behavioral outcomes, as our results showed that low detachment in the evening stimulated the use of ICT later in the day, although the effect was rather small in size. This finding adds to research on other behavioral consequences, including recovery activities (for a review, see Sonnentag et al., 2017), and broadens our understanding of the activities individuals choose to do when they cannot disengage from work.

Interestingly, our study revealed that making progress on certain tasks can help employees to better detach in the late evening, but only on days when employees planned to use their ICTs after work. This might indicate that planned ICT use to finish some sort of smaller tasks in the early evening could contribute to successful detachment via task progress, 
supporting earlier studies that showed similar effects over the course of a weekend (Syrek \& Antoni, 2014; Syrek et al., 2017; Weigelt \& Syrek, 2017). One might even speculate that completing such tasks in the evening can lead to mastery experience, another form of recovery experience (Sonnentag $\&$ Fritz, 2007). However, we are well aware that this is a post hoc interpretation and that the result is rather preliminary because we did not examine directional effects of ICT use and task progress at T1. Moreover, we want to emphasize that persistent ICT use for work leaves little time for pursuing beneficial recovery activities, such as relaxing, physical exercise, or social activities, which suggests a tension between these behaviors. In line with this, the results on the between-level of analysis suggest that individuals with a high level of planned ICT use experience poorer detachment. In the future, the interplay of after-hours ICT use with recovery activities that affect recovery experiences, including detachment and mastery, needs to be explored further, potentially considering both within- and between-level effects.

Contrary to expectations, our results indicated that ICT use did not predict task progress in the late evening, although the correlations at $\mathrm{T} 1$ and $\mathrm{T} 2$ were significantly positive: ICT use may therefore not inevitably be a useful means to complete bigger tasks that require more time. The reasons for ICT use could play a role. For some employees, ICT use in the evening might be a strategy that helps them to detach or to cope with pressing job demands, but others might start working simply out of habit without thinking about it (Heitmayer \& Lahlou, 2021; Middleton, 2008). Only when employees schedule additional work and are able to make certain progress, it might help to better detach. However, our results showed similar relationships for both planned and unplanned ICT use in the early-to-late evening process. It would therefore be interesting to more systematically consider, for example, characteristics of the task or state attributes of the individual for work-related and recovery activities after hours to uncover the mechanisms emanating from ICT use. Given the identified reverse causal effects of task progress on ICT use and detachment for days on which work-related ICT use was planned, such mechanisms might considerably depend on whether ICTs are used voluntarily to experience mastery or detachment, or result from a lack of self-control.

The pattern of findings (no significant cross-lagged path between ICT use and later detachment; significant crosslagged path between detachment and later ICT use) in our study may further suggest that ICT use for work in the evening can be considered a form of job performance (instead of as a stressor), which is defined as individuals' actions related to organizational goals (Campbell et al., 1993). Individuals might use their ICT for work to share information with a colleague or to arrange appointments for the following days, all of which contribute to organizational goals. In fact, communicating effectively with colleagues is a form of teammember proficiency (Griffin et al., 2007) and might include responding to emails after hours. Following this perspective, dealing with this behavior needs to be embedded in the broader research on human resource management, including reward systems and work design (Wang et al., 2020). When ICT use for work in the evening is formally or informally rewarded, efforts of limiting it might be futile, especially when workload is high and others depend on the input of a person. Anecdotal evidence is provided by a German automotive manufacturer, who technically limited employees' access to work emails after hours. As a result, some managers sent work-related emails to their secretary's private email account to ensure information flow and allocation of tasks.

Finally, this study contributes to research by investigating a full day-level longitudinal design that helps provide evidence for the causal direction of effects. Diary studies have become increasingly pervasive in organizational research (Ohly et al., 2010), since they allow scholars to examine the dynamics of relevant factors, making them especially appropriate for research on recovery and ICT use. By assessing data multiple times a day (and by analyzing within and between-level effects), we respond to calls to pay more attention to temporal dynamics over the course of an evening (McCormick et al., 2020; Sonnentag et al., 2017). Additionally, longitudinal models in applied research are still rare in general, despite the strong encouragement to implement them more widely (Zapf et al., 1996). Our research shows the value of implementing such a design in a diary study, as we were able to provide evidence for the direction of effect between work-related ICT use and detachment. This can change the understanding of ICT use as a stressor and prompts new questions about its role in research on unfinished tasks and the interplay between the work and home domains.

\section{Practical Implications}

By showing that ICT use is rather a behavioral consequence than a stressor per se, our study has important implications on how to deal with the phenomenon in organizations. First, because poor detachment is due to too much work and unfinished tasks, the amount of work needs to be targeted in order to improve detachment and well-being. Examination of individual reasons for ICT use in the evening revealed that planned ICT use might be more beneficial than unplanned ICT use, which occurs, e.g., when employees respond to signals, suggesting that the more spontaneous ICT use needs to be addressed.

Organizational measures to protect employees' free time and well-being (e.g., Gadeyne et al., 2018), including asking employees to turn off ICT so as not to receive any signals or 
technical measures that restrict e-mail delivery after hours or account access from home may not have the intended effects unless accompanied by additional interventions. Such interventions may consist of training employees in strategies to mentally leave unfinished tasks behind, such as managing the boundaries between the work and private domain through certain boundary tactics (Kreiner et al., 2009), creating specific plans for the completion of unfinished tasks (Smit, 2016), or teaching them how to detach from work (Hahn et al., 2011).

Furthermore, leaders have several options to prevent potential negative consequences of ICT use for their followers. First, instead of telling them not to use ICT at all, leaders could support employees in setting boundaries for work-related ICT use (Park et al., 2020), in encouraging ICT use for work in a way that fits with one's preferences (Barber \& Jenkins, 2014; Kreiner et al., 2009), and in raising awareness that potentially detrimental effects of work-related ICT use can be alleviated when goals for its use are set, e.g., focusing on specific pressing work tasks that need to be finished (Fenner \& Renn, 2010).

\section{Limitations}

This study has some limitations that should be considered. First, although the use of a longitudinal autoregressive design is a considerable strength of this study, this method does not provide final certainty about causality, as would be the case with an experimental design (Finkel, 1995; Zapf et al., 1996). Specifically, it is not possible to rule out all potential alternative explanations for the effects between variables. Nevertheless, conducting a study with an experimental design would be a difficult endeavor, since workrelated ICT use can only be reliably assessed in field studies. Additionally, conducting a longitudinal autoregressive design is preferable to simple cross-sectional research when the goal is to infer directions of relationships in a field setting (Zapf et al., 1996).

Second, this study only relied on self-report measures, which can lead to common-method bias (Podsakoff et al., 2003). While it would have been preferable to measure ICT use for work in a more objective way to avoid commonmethod bias as well as for accuracy, e.g., with a tracking app on the employees work-related ICT, this approach was not feasible for this study and is difficult to achieve for technological and privacy reasons. However, as the variables were measured at two measurement times, with different response formats and in part referring to measurable facts (length of ICT use), and as the effects of detachment, ICT use, and task progress were controlled for their T1 impact, any bias caused by the use of a single method should be minimized (Podsakoff et al., 2012).
A third limitation is the time lag we used. As this is, to our knowledge, the first diary study in this field implementing a longitudinal autoregressive design within the evening, the appropriate time lag is not yet clear. Particularly in view of the small effect size of cross-lagged effects identified in our study, future studies could implement varying time lags to investigate and compare the effect of different time lags.

A fourth limitation of this study was the significant dropout in our study. We therefore controlled for whether individuals who did not complete the entire diary study (between-level attrition) or who dropped out during a given day (within-level attrition) differed from those who completed everything (cf. Lugtig, 2014). While no significant differences emerged in terms of sociodemographic variables and most of the study variables, we did find that the participants who reported more unfinished tasks were less likely to participate on each day.

Fifth, although around $20 \%$ of the working population in Germany are equipped with mobile devices for work purposes at the time of the study (Statistisches Bundesamt, 2017; ZEW, 2015), the requirement to use separate devices for work and private life may limit the generalizability of our study. While this was important to avoid eliciting workrelated ICT use after answering a survey and to minimize bias in the measurement of our focal variable, this might have screened out employees who set fewer boundaries for work-related ICT use at home by using the same device for their work and private life. It has been shown that employees who fail to set limits for work-related ICT use suffer more (Barber \& Jenkins, 2014). In contrast to this argument, however, a study by Dora et al. (2019) found that employees who are provided with separate ICT by their employer (which might be considered a boundary management strategy) are more likely to use it for work at home and therefore have difficulties in setting boundaries. Nevertheless, we acknowledge that with this criterion we might have rejected individuals who experience more negative consequences due to work-related ICT use than the participants in our sample.

Finally, the measurement of ICT use deserves some comment. One might argue that a differentiation of devices is necessary to determine which kind of ICT use is most detrimental (cf. Gadeyne et al., 2018). Due to the repeated assessment of ICT use for evening work, we were limited in the number of survey items and could thus only distinguish between planned and unplanned use, but not between the type of device used.

\section{Directions for Future Research}

Some suggestions can be made for future research. First, we recommend that future studies employ designs where the unique effects of ICT use and detachment can be investigated. Our results showed that disentangling the two variables 
changed our understanding of cause and effect regarding workrelated ICT use. While this opens up new ways of looking at the immediate impact of work-related ICT use on a day-level, studies using other time frames are necessary to differentiate effects, e.g., long-term effects of frequent or prolonged ICT use that may negatively affect well-being because it reduces time available for recovery (Geurts \& Sonnentag, 2006; Söderström et al., 2012).

Second, since our results show that work-related ICT use did not impair detachment, it will be useful to explore the actual role of work-related ICT use during leisure time further. It remains unresolved if and how the use of ICT for work during leisure time can affect employee well-being and behavior. For example, it needs to be determined how employees can use ICT in a strategic way to achieve detachment and under which conditions. Differentiated measurement of ICT use for work, including the motivation for doing so, is necessary in this regard (cf. Hu et al., 2021). Because our task progress scale did not distinguish between task progress and work task completion, this could be explored in the future to test whether work task completion reverses effects or increases mastery experiences.

Finally, it would be interesting to study bidirectional effects between detachment and additional employee behavior over the course of one evening. Scholars are encouraged to learn more about specific behaviors employees engage in when they cannot detach from work. Individuals might also choose to engage in behaviors that are more detrimental to health and well-being than ICT use, for example, drinking alcohol or ruminating about negative job experiences. Further research is needed to explore which activities are chosen, and why. In a similar vein, it would be useful to uncover strategies that help employees with detaching from work, especially when they were unable to do so at an earlier time.

\section{Conclusion}

There are two main takeaways from this study. First, when employees are confronted with unfinished tasks and consequently have difficulty detaching from work, they use ICT to work. Secondly, work-related ICT use does neither impair individual levels of detachment nor considerably increases perceived task progress later on the same day. In summary, it can be stated that the classification of work-related ICT use as a stressor must be questioned, as it seems more likely that the behavior is confounded with its sources, namely, unfinished work tasks and impaired detachment.

Funding Open Access funding enabled and organized by Projekt DEAL.
Open Access This article is licensed under a Creative Commons Attribution 4.0 International License, which permits use, sharing, adaptation, distribution and reproduction in any medium or format, as long as you give appropriate credit to the original author(s) and the source, provide a link to the Creative Commons licence, and indicate if changes were made. The images or other third party material in this article are included in the article's Creative Commons licence, unless indicated otherwise in a credit line to the material. If material is not included in the article's Creative Commons licence and your intended use is not permitted by statutory regulation or exceeds the permitted use, you will need to obtain permission directly from the copyright holder. To view a copy of this licence, visit http://creativecommons.org/licenses/by/4.0/.

\section{References}

Adachi, P., \& Willoughby, T. (2015). Interpreting effect sizes when controlling for stability effects in longitudinal autoregressive models: Implications for psychological science. European Journal of Developmental Psychology, 12(1), 116-128. https://doi.org/10. 1080/17405629.2014.963549

American Psychological Association. (2013). Communication technology: Implications for work and well-being. Retrieved April 29, 2019, from http://www.apaexcellence.org/assets/general/2013work-and-communication-technology-survey-final.pdf

Ashforth, B. E., Kreiner, G. E., \& Fugate, M. (2000). All in a day's work: Boundaries and micro role transitions. Academy of Management Review, 25(3), 472-491. https://doi.org/10.5465/AMR. 2000.3363315

Barber, L. K., \& Jenkins, J. S. (2014). Creating technological boundaries to protect bedtime: Examining work-home boundary management, psychological detachment and sleep. Stress and Health, 30(3), 259-264. https://doi.org/10.1002/smi.2536

Barley, S. R., Meyerson, D. E., \& Grodal, S. (2011). E-mail as a source and symbol of stress. Organization Science, 22(4), 887-906. https://doi.org/10.1287/ORSC.1100.0573

Bennett, A. A., Bakker, A. B., \& Field, J. G. (2018). Recovery from work-related effort: A meta-analysis. Journal of Organizational Behavior, 39(3), 262-275. https://doi.org/10.1002/JOB.2217

Berset, M., Elfering, A., Lüthy, S., Lüthi, S., \& Semmer, N. K. (2011). Work stressors and impaired sleep: Rumination as a mediator. Stress and Health, 27(2), e71-82. https://doi.org/10.1002/smi. 1337

Boswell, W. R., \& Olson-Buchanan, J. B. (2007). The use of communication technologies after hours: The role of work attitudes and work-life conflict. Journal of Management, 33(4), 592-610. https://doi.org/10.1177/0149206307302552

Braukmann, J., Schmitt, A., Ďuranová, L., \& Ohly, S. (2018). Identifying ICT-related affective events across life domains and examining their unique relationships with employee recovery. Journal of Business and Psychology, 33(4), 529-544. https://doi.org/10. 1007/s10869-017-9508-7

Campbell, J. P., McCloy, R., Oppler, S., \& Sager, \& C. (1993). A theory of performance. In N. Schmitt \& W. C. Borman (Eds.), Personnel selection in organizations (pp. 35-70). Jossey-Bass.

David, K., Bieling, G., Bohnstedt, D., Jandt, S., Ohly, S., Robnagel, A., Schmitt, A., Steinmetz, R., Stock-Homburg, R., \& Wacker, A. (2014). Balancing the online life: Mobile usage scenarios and strategies for a new communication paradigm. IEEE Vehicular Technology Magazine, 9(3), 72-79. https://doi.org/10.1109/MVT. 2014.2333763

Day, A., Scott, N., \& Kelloway, K. (2010). Information and communication technology: Implications for job stress and employee wellbeing. In P. L. Perrewé \& D. C. Ganster (Eds.), Research in occupational stress and well being: New developments in theoretical 
and conceptual approaches to job stress (8th ed., pp. 317-350). Emerald.

Derks, D., Brummelhuis, L. L. ten, Zecic, D., \& Bakker, A. B. (2014a). Switching on and off ... : Does smartphone use obstruct the possibility to engage in recovery activities? European Journal of Work and Organizational Psychology, 23(1), 80-90. https://doi.org/10. 1080/1359432X.2012.711013

Derks, D., van Mierlo, H., \& Schmitz, E. B. (2014b). A diary study on work-related smartphone use, psychological detachment and exhaustion: Examining the role of the perceived segmentation norm. Journal of Occupational Health Psychology, 19(1), 74-84. https://doi.org/10.1037/a0035076

Derks, D., van Duin, D., Tims, M., \& Bakker, A. B. (2015). Smartphone use and work-home interference: The moderating role of social norms and employee work engagement. Journal of Occupational and Organizational Psychology, 88(1), 155-177. https:// doi.org/10.1111/JOOP.12083

Diaz, I., Chiaburu, D. S., Zimmerman, R. D., \& Boswell, W. R. (2012). Communication technology: Pros and cons of constant connection to work. Journal of Vocational Behavior, 80(2), 500-508. https:// doi.org/10.1016/J.JVB.2011.08.007

Dora, J., van Hooff, M. L. M., Geurts, S. A. E., Hooftman, W. E., \& Kompier, M. A. J. (2019). Characterizing work-related smartphone use at home and private smartphone use at work using latent class analysis. Occupational Health Science, 3(2), 187-203. https://doi.org/10.1007/s41542-019-00040-6

Dunn, T. J., Baguley, T., \& Brunsden, V. (2014). From alpha to omega: A practical solution to the pervasive problem of internal consistency estimation. British Journal of Psychology, 105(3), 399-412. https://doi.org/10.1111/bjop.12046

Ďuranová, L., \& Ohly, S. (2016). Persistent work-related technology use, recovery and well-being processes: Focus on supplemental work after hours. Springer.

Eichberger, C., Derks, D., \& Zacher, H. (2020). Technology-assisted supplemental work, psychological detachment, and employee well-being: A daily diary study. German Journal of Human Resource Management. Advance online publication. https://doi. org/10.1177/2397002220968188

Etzion, D., Eden, D., \& Lapidot, Y. (1998). Relief from job stressors and burnout: Reserve service as a respite. Journal of Applied Psychology, 83(4), 577-585. https://doi.org/10.1037/0021-9010. 83.4.577

Fenner, G. H., \& Renn, R. W. (2010). Technology-assisted supplemental work and work-to-family conflict: The role of instrumentality beliefs, organizational expectations and time management. Human Relations, 63(1), 63-82. https://doi.org/10.1177/00187 26709351064

Finkel, S. E. (1995). Causal analysis with panel data. Sage.

Frese, M., \& Zapf, D. (1988). Methodological issues in the study of work stress: Objective vs. subjective measurement and the question of longitudinal studies. In C. L. Cooper \& R. Payne (Eds.), Causes, coping, and consequences of stress at work (pp. 375411). Wiley.

Gadeyne, N., Verbruggen, M., Delanoeije, J., \& de Cooman, R. (2018). All wired, all tired? Work-related ICT-use outside work hours and work-to-home conflict: The role of integration preference, integration norms and work demands. Journal of Vocational Behavior, 107, 86-99. https://doi.org/10.1016/J.JVB.2018.03.008

Geurts, S. A. E., \& Sonnentag, S. (2006). Recovery as an explanatory mechanism in the relation between acute stress reactions and chronic health impairment. Scandinavian Journal of Work,
Environment \& Health, 32(6), 482-492. https://doi.org/10.5271/ sjweh. 1053

Griffin, M. A., Neal, A., \& Parker, S. K. (2007). A new model of work role performance: Positive behavior in uncertain and interdependent contexts. Academy of Management Journal, 50(2), 327-347. https://doi.org/10.5465/amj.2007.24634438

Hahn, V. C., Binnewies, C., Sonnentag, S., \& Mojza, E. J. (2011). Learning how to recover from job stress: Effects of a recovery training program on recovery, recovery-related self-efficacy, and well-being. Journal of Occupational Health Psychology, 16(2), 202-216. https://doi.org/10.1037/a0022169

Hayduk, L. A., \& Littvay, L. (2012). Should researchers use single indicators, best indicators, or multiple indicators in structural equation models? BMC Medical Research Methodology, 12, 159. https:// doi.org/10.1186/1471-2288-12-159

Heitmayer, M., \& Lahlou, S. (2021). Why are smartphones disruptive? An empirical study of smartphone use in real-life contexts. Computers in Human Behavior, 116, 106637. https://doi.org/10. 1016/j.chb.2020.106637

Hox, J. J. (2002). Multilevel analysis: Techniques and applications. Erlbaum.

Hu, X., Park, Y., Day, A., \& Barber, L. K. (2021). Time to disentangle the information and communication technology (ICT) constructs: Developing a taxonomy around ICT use for occupational health research. Advance online publication. https://doi.org/10.1007/ s41542-021-00085-6

Indeed. (2016). Wie Deutschland arbeitet: [How Germany is working]. Retrieved November 21, 2018, from https://www.presseportal.de/ $\mathrm{pm} / 110144 / 3294536$

Kam, C. C. S., \& Fan, X. (2020). Investigating response heterogeneity in the context of positively and negatively worded items by using factor mixture modeling. Organizational Research Methods, 23(2), 322-341. https://doi.org/10.1177/1094428118790371

Kreiner, G. E., Hollensbe, E. C., \& Sheep, M. L. (2009). Balancing borders and bridges: Negotiating the work-home interface via boundary work tactics. Academy of Management Journal, 52(4), 704-730. https://doi.org/10.5465/AMJ.2009.43669916

Lanaj, K., Johnson, R. E., \& Barnes, C. M. (2014). Beginning the workday yet already depleted? Consequences of late-night smartphone use and sleep. Organizational Behavior and Human Decision Processes, 124(1), 11-23. https://doi.org/10.1016/J.OBHDP. 2014.01.001

Little, T. D., Preacher, K. J., Selig, J. P., \& Card, N. A. (2007). New developments in latent variable panel analyses of longitudinal data. International Journal of Behavioral Development, 31(4), 357-365. https://doi.org/10.1177/0165025407077757

Lugtig, P. (2014). Panel attrition: Separating stayers, fast attriters, gradual attriters, and lurkers. Sociological Methods \& Research, 43(4), 699-723. https://doi.org/10.1177/0049124113520305

Matusik, S. F., \& Mickel, A. E. (2011). Embracing or embattled by converged mobile devices? Users' experiences with a contemporary connectivity technology. Human Relations, 64(8), 1001-1030. https://doi.org/10.1177/0018726711405552

McCormick, B. W., Reeves, C. J., Downes, P. E., Li, N., \& Ilies, R. (2020). Scientific contributions of within-person research in management: Making the juice worth the squeeze. Journal of Management, 46(2), 321-350. https://doi.org/10.1177/0149206318788435

McDonald, R. P. (1999). Test theory: A unified treatment. Erlbaum.

Middleton, C. A. (2008). Do mobile technologies enable work-life balance? Dual perspectives on Blackberry usage for supplemental work. In D. Hislop (Ed.), Mobility and technology in the workplace (9th ed., pp. 209-224). Routledge. 
Muthén, B. O., \& Muthén, L. K. (1998-2017). Mplus user's guide. (8th ed.). Muthén \& Muthén.

Ohly, S., \& Latour, A. (2014). Work-related smartphone use and wellbeing in the evening. Journal of Personnel Psychology, 13(4), 174-183. https://doi.org/10.1027/1866-5888/a000114

Ohly, S., Sonnentag, S., Niessen, C., \& Zapf, D. (2010). Diary studies in organizational research. Journal of Personnel Psychology, 9(2), 79-93. https://doi.org/10.1027/1866-5888/a000009

Park, Y., Fritz, C., \& Jex, S. M. (2011). Relationships between workhome segmentation and psychological detachment from work: The role of communication technology use at home. Journal of Occupational Health Psychology, 16(4), 457-467. https://doi.org/ 10.1037/a0023594

Park, Y., \& Jex, S. M. (2011). Work-home boundary management using communication and information technology. International Journal of Stress Management, 18(2), 133-152. https://doi.org/ 10.1037/a0022759

Park, Y., Liu, Y., \& Headrick, L. (2020). When work is wanted after hours: Testing weekly stress of information communication technology demands using boundary theory. Journal of Organizational Behavior, 41(6), 518-534. https://doi.org/10.1002/job.2461

Peifer, C., Syrek, C., Ostwald, V., Schuh, E., \& Antoni, C. H. (2020). Thieves of flow: How unfinished tasks at work are related to flow experience and wellbeing. Journal of Happiness Studies, 21(5), 1641-1660. https://doi.org/10.1007/s10902-019-00149-Z

Petrescu, M. (2013). Marketing research using single-item indicators in structural equation models. Journal of Marketing Analytics, 1(2), 99-117. https://doi.org/10.1057/jma.2013.7

Podsakoff, P. M., MacKenzie, S. B., Lee, J.-Y., \& Podsakoff, N. P. (2003). Common method biases in behavioral research: A critical review of the literature and recommended remedies. Journal of Applied Psychology, 88(5), 879-903. https://doi.org/10.1037/ 0021-9010.88.5.879

Podsakoff, P. M., MacKenzie, S. B., \& Podsakoff, N. P. (2012). Sources of method bias in social science research and recommendations on how to control it. Annual Review of Psychology, 63, 539-569. https://doi.org/10.1146/annurev-psych-120710-100452

Preacher, K. J., Zhang, Z., \& Zyphur, M. J. (2016). Multilevel structural equation models for assessing moderation within and across levels of analysis. Psychological Methods, 21(2), 189-205. https://doi. org/10.1037/met0000052

Rasmussen, J. L., \& Dunlap, W. P. (1991). Dealing with nonnormal data: Parametric analysis of transformed data vs nonparametric analysis. Educational and Psychological Measurement, 51(4), 809-820. https://doi.org/10.1177/001316449105100402

Raykov, T. (2005). Analysis of longitudinal studies with missing data using covariance structure modeling with full-information maximum likelihood. Structural Equation Modeling, 12(3), 493-505. https://doi.org/10.1207/s15328007sem1203_8

Schermelleh-Engel, K., Moosbrugger, H., \& Müller, H. (2003). Evaluating the fit of structural equation models: Tests of significance and descriptive goodness-of-fit measures. Methods of Psychological Research, 8(2), 23-74.

Smit, B. W. (2016). Successfully leaving work at work: The self-regulatory underpinnings of psychological detachment. Journal of Occupational and Organizational Psychology, 89(3), 493-514. https://doi.org/10.1111/JOOP.12137

Söderström, M., Jeding, K., Ekstedt, M., Perski, A., \& Akerstedt, T. (2012). Insufficient sleep predicts clinical burnout. Journal of Occupational Health Psychology, 17(2), 175-183. https://doi. org/10.1037/a0027518
Sonnentag, S. (2001). Work, recovery activities, and individual wellbeing: A diary study. Journal of Occupational Health Psychology, 6(3), 196-210. https://doi.org/10.1037//1076-8998.6.3.196

Sonnentag, S. (2015). Dynamics of well-being. Annual Review of Organizational Psychology and Organizational Behavior, 2, 261293. https://doi.org/10.1146/annurev-orgpsych-032414-111347

Sonnentag, S., \& Bayer, U.-V. (2005). Switching off mentally: Predictors and consequences of psychological detachment from work during off-job time. Journal of Occupational Health Psychology, 10(4), 393-414. https://doi.org/10.1037/1076-8998.10.4.393

Sonnentag, S., \& Fritz, C. (2007). The Recovery Experience Questionnaire: Development and validation of a measure for assessing recuperation and unwinding from work. Journal of Occupational Health Psychology, 12(3), 204-221. https://doi.org/10.1037/10768998.12.3.204

Sonnentag, S., \& Fritz, C. (2015). Recovery from job stress: The stressor-detachment model as an integrative framework. Journal of Organizational Behavior, 36(S1), S72-S103. https://doi.org/ 10.1002/job.1924

Sonnentag, S., \& Kruel, U. (2006). Psychological detachment from work during off-job time: The role of job stressors, job involvement, and recovery-related self-efficacy. European Journal of Work and Organizational Psychology, 15(2), 197-217. https:// doi.org/10.1080/13594320500513939

Sonnentag, S., Venz, L., \& Casper, A. (2017). Advances in recovery research: What have we learned? What should be done next? Journal of Occupational Health Psychology, 22(3), 365-380. https:// doi.org/10.1037/ocp0000079

Statistisches Bundesamt. (2017). Unternehmen und Arbeitsstätten Nutzung von Informations- und Kommunikationstechnologien in Unternehmen [Organizations and workplaces - The use of information and communication technology in organizations]. Retrieved October 5, 2021, from https://www.statistischebiblioth ek.de/mir/receive/DESerie_mods_00001026

Syrek, C. J., \& Antoni, C. H. (2014). Unfinished tasks foster rumination and impair sleeping - particularly if leaders have high performance expectations. Journal of Occupational Health Psychology, 19(4), 490-499. https://doi.org/10.1037/a0037127

Syrek, C. J., Weigelt, O., Peifer, C., \& Antoni, C. H. (2017). Zeigarnik's sleepless nights: How unfinished tasks at the end of the week impair employee sleep on the weekend through rumination. Journal of Occupational Health Psychology, 22(2), 225-238. https:// doi.org/10.1037/ocp0000031

Wang, B., Liu, Y., \& Parker, S. K. (2020). How does the use of information communication technology affect individuals? A work design perspective. Academy of Management Annals, 14(2), 695-725. https://doi.org/10.5465/annals.2018.0127

Weigelt, O., \& Syrek, C. J. (2017). Ovsiankina's great relief: How supplemental work during the weekend may contribute to recovery in the face of unfinished tasks. International Journal of Environmental Research and Public Health, 14(12). https://doi.org/10. 3390/ijerph14121606

Wendsche, J., \& Lohmann-Haislah, A. (2017). A meta-analysis on antecedents and outcomes of detachment from work. Frontiers in Psychology, 7, 2072. https://doi.org/10.3389/fpsyg.2016.02072

Wright, K. B., Abendschein, B., Wombacher, K., O'Connor, M., Hoffman, M., Dempsey, M., Krull, C., Dewes, A., \& Shelton, A. (2014). Work-related communication technology use outside of regular work hours and work life conflict: The influence of communication technologies on perceived work life conflict, burnout, job satisfaction, and turnover intentions. Management Communication Quarterly, 28(4), 507-530. https://doi.org/10.1177/08933 18914533332 
Yang, Y., \& Green, S. B. (2011). Coefficient alpha: A reliability coefficient for the 21st century? Journal of Psychoeducational Assessment, 29(4), 377-392. https://doi.org/10.1177/0734282911406668

Zapf, D., Dormann, C., \& Frese, M. (1996). Longitudinal studies in organizational stress research: A review of the literature with reference to methodological issues. Journal of Occupational Health Psychology, 1(2), 145-169. https://doi.org/10.1037/1076-8998.1. 2.145

Zeigarnik, B. (1938). On finished and unfinished tasks. In W. D. Ellis (Ed.), A source book of Gestalt psychology (pp. 300-314). Kegan Paul, Trench, Trubner \& Company. https://doi.org/10.1037/ 11496-025
ZEW. (2015). IKT-Report: Unternehmensbefragung zur Nutzung von Informations- und Kommunikationstechnologien [ICT-report: Business survey on the use of information and communication technology].

Publisher's Note Springer Nature remains neutral with regard to jurisdictional claims in published maps and institutional affiliations. 